\title{
KINERJA QUAY CONTAINER CRANE DALAM KEGIATAN BONGKAR MUAT PETIKEMAS DI KSO TERMINAL PETIKEMAS KOJA JAKARTA UTARA
}

\author{
* Lis Lesmini ${ }^{1}$, Daeng Rifqi Fadhlurrahman ${ }^{2}$ \\ ${ }^{1,2,3}$ Institut Transportasi dan Logistik Trisakti, Jakarta, Indonesia
}

*Email Korespondensi:

lies.1969@yahoo.com

\section{ARTIKEL INFORMASI}

Diterima:

25 Juni 2021

Direvisi:

12 Juli 2021

Dipublikasi:

22 Juli 2021

\begin{abstract}
ABSTRAK
Tujuan penelitian ini adalah untuk mengetahui Pengaruh Kinerja Quay Container Crane Terhadap Kelancaran Kegiatan Bongkar Muat Petikemas di Terminal Petikemas Koja, Jakarta Utara. Teknik pengumpulan data melalui wawancara dan penyebaran kuesioner. Jenis penelitian deskriptif kuantitatif, sumber data yang digunakan adalah data primer dan data sekunder, teknik analisis data dengan analisis regresi linear sederhana, koefisien korelasi, koefisien penentu, uji hipotesis, uji validitas, dan uji reliabilitas. Populasi penelitian sebanyak 37 orang operator QCC dan sampel penelitian sebanyak 37 orang. Teknik sampling menggunakan sampel jenuh. Hasil analisis menunjukan adanya pengaruh dari kinerja Quay Container Crane dan kelancaran kegiatan bongkar muat yang ditunjukan dengan persamaan garis regresi linear sederhana yaitu: $\mathrm{Y}=9,679+0,696 \mathrm{X}$, artinya, jika terjadi perubahan kinerja QCC (variabel X) bertambah, maka kelancaran kegiatan bongkar muat akan meningkat sebesar 0,696 dengan konstanta (a) 9,679. Analisis Koefisien Korelasi ( $\mathrm{r}$ ) = 0,610 artinya kinerja QCC (variabel X) dengan kelancaran kegiatan bongkar muat memiliki pengaruh hubungan yang kuat dan positif. Analisis Koefisien Penentu (KP) sebesar 37,2\%. Berdasarkan hasil uji hipotesis menunjukan thitung > ttabel atau 5,746 > 2,030, sehingga H0 ditolak dan Ha diterima, artinya adanya pengaruh kinerja QCC terhadap kelancaran kegiatan bongkar muat.
\end{abstract}

Kata Kunci: Kinerja Quay Container Crane, Bongkar Muat Petikemas, Produktivitas Bongkar Muat

\section{PENDAHULUAN}

Pelabuhan Tanjung Priok merupakan pelabuhan terbesar di Indonesia dengan aktifitas tersibuk, baik oleh lalu lintas kapal yang akan masuk atau keluar pelabuhan maupun kendaraan (darat) yang mengangkut petikemas, terminal petikemas yang ada di Tanjung Priok yaitu KSO (Kerja Sama Operasi) Terminal Petikemas Koja atau biasa disebut dengan KSO TPK Koja. Biasanya perusahaan Shipping Line sangat menggemari terminal petikemas yang mempunyai waktu bongkar muatnya singkat dan cepat. Hal ini dikarenakan semakin cepat proses bongkar muat maka semakin sedikit waktu yang dibutuhkan dipelabuhan, sehingga semakin rendah pula biaya (cost) yang harus dikeluarkan oleh kapal tersebut. 
Pertumbuhan Indonesia pada awal 1990-an telah menyebabkan peningkatan kegiatan ekspor dan impor melalui pelabuhan Tanjung Priok. Untuk memenuhi permintaan yang meningkat tajam dari layanan penanganan petikemas, perusahaan milik negara, PT Pelabuhan Indonesia II (Persero) bekerja sama dengan perusahaan swasta, PT Hutchison Ports Indonesia, bersama-sama mengembangkan terminal yang benar-benar baru, Koja Container Terminal (Terminal Petikemas Koja-TPK KOJA). Kedua perusahaan ini juga telah membentuk Operasi Bersama (Join Operation) untuk menangani operasi harian terminal. Dengan melakukan beberapa program optimalisasi, kapasitasnya telah meningkat dari 680 ribu menjadi lebih dari 1 juta TEUS petikemas per tahun, dan siap melayani kapal-kapal petikemas generasi keempat yang besar.

KSO Terminal Petikemas Koja merupakan terminal petikemas pertama di Indonesia yang dioperasikan bersama pemerintah dengan swasta yang bertujuan memberikan kontribusi pertumbuhan bagi negara. Berlokasi di Jl. Digul No.1 Tanjung Priok Jakarta Utara, Jakarta 14310, Indonesia. Saat ini KSO TPK Koja menerapkan sistem operasi yang bernama next Generation (nGen) dimana perubahan sistem operasi ini diubah pada tahun 2003 dahulu KSO TPK Koja mengusung sistem operasi yang bernama NAVIS. Sistem tersebut dirancang agar dapat link dengan customer system, sehingga dapat berhubungan online secara cepat. Hal ini membuat pelanggan dapat melacak posisi petikemas, rencana penumpukan, dan kapal yang digunakan. Untuk pertumbuhan yang lebih baik, saat ini KSO TPK Koja mempunyai luas area penumpukan 21,80 Ha, Kapasitas Penumpukan Impor 7.560 TEUs, Kapasitas Penumpukan Ekspor 7696 TEUs, dan Kapasitas Penumpukan Reefer ada 310 plug. Sedangkan panjang kademeter KSO TPK Koja ialah 650 meter kade, mempunyai Lebar Dermaga 40 m, dan kedalaman kolam -14 MLWS.

Sebagai terminal petikemas yang mempunyai aktifitas yang sibuk tentunya harus memiliki peralatan bongkar muat yang dalam kondisi baik dan prima untuk melancarkan semua kegiatan bongkar muat yang ada di terminal petikemas tersebut. Namun dalam kegiatan proses bongkar muat tidak selalu berjalan lancar sepeti apa yang diharapkan, terkadang ada banyak kendala yang sangat mengganggu proses kegiatan bongkar muat yang bisa menyebabkan delay untuk Loading dan Discharge dari kapal atau ke kapal.

Dalam melakukan operasi terminal agar kegiatan di terminal berjalan lancar tentunya juga harus dibutuhkan sistem komunikasi yang baik antara anggota lapangan dengan anggota yang ada di control tower. Sekarang ini KSO Terminal Petikemas Koja memakai sistem N-Gen yang digunakan di lokasi KSO Terminal Petikemas Koja yang dimana N-Gen merupakan sistem baru yang diterapkan oleh KSO Terminal Petikemas Koja. Dahulu saat N-Gen belum diterapkan, KSO Terminal Petikemas Koja menggunakan sistem yang bernama NAVIS. N-Gen dibuat oleh perusahaan Hutchinson Port dimana perusahan tersebut merupakan induk dari KSO Terminal Petikemas Koja yang melakukan kerja sama dengan PT. Pelindo (Pelabuhan Indonesia). Dengan ada nya sistem baru yang telah diterapkan akan meminimalkan terjadinya kesalahpahaman antara pihak satu dengan yang lainnya. Selama melakukan operasi kegiatan bongkar muat petikemas, perlu ditentukan jumlah anggota yang akan melakukan kegiatan bongkar atau muat petikemas tersebut. Di KSO Terminal Petikemas Koja saat ini memiliki beberapa Gang/Regu. Satu regu terdiri dari 12 orang Tenaga Kerja Bongkar Muat (TKBM). TKBM tersebut akan di booking berdasarkan kerja kapal ataupun dengan jumlah Quay Container Crane yang akan digunakan selama waktu beroperasi.

Dalam melakukan operasi bongkar muat KSO TPK Koja mempunyai peralatan yaitu 7 unit Quay Container Crane (QCC) yang digunakan untuk melakukan operasi bongkar atau muat petikemas di pinggir dermaga, 25 unit Rubber Tyred Gantry Crane (RTGC) yang digunakan untuk men stack petikemas pada saat petikemas sudha berada di Container Yard (CY), 48 unit Head Truck yang digunakan untuk mengangkut petikemas dari dermaga ke lapangan penumpukan maupun dari lapangan penumpukan ke dermaga, dan 3 unit Reach Staker. KSO Terminal Petikemas Koja mempunyai beberapa pelanggan yang menggunakan terminal untuk stack petikemas, diantaranya ialah China Shipping Container Line, Gold Star Line LTD, Hapag-Lloyd, Hanjin, Heung-A Shipping, HMM, KMTC Line, K-Line, MOL, SINOKOR, TEMAS Line, Wan Hai Lines LTD, BEN LINE AGENCIES, SPIL, ANL, Regional Container Lines (RCL), MSC.

Permasalahan dalam penelitian ini adalah mengenai QCC (Quay Container Crane) yang sering bermasalah dalam melakukan kegiatan bongkar muat. Quay Container Crane harus selalu dalam keadaan prima ketika akan digunakan. Untuk menyatakan seberapa banyak petikemas yang dibongkar dan dimuat mempergunakan hitungan yang bernama GCR (Gross Crane Rate) dulu bernama BCH (Box Crane per Hour) dan VOR (Vessel Operation Rate) dulu bernama BSH (Box Ship per Hour). GCR menyatakan seberapa banyak petikemas yang dapat dibongkar dan dimuat pada setiap Quay Container Crane dalam waktu satu jam. Sedangkan VOR menunjukan seberapa banyak petikemas yang dapat di bongkar dan dimuat pada satu kapal dalam waktu satu jam.GCR dan VOR di KSO Terminal Petikemas Koja sendiri memiliki target 26 box per jam 
untuk GCR dan 65 box per jam untuk VOR. Kecepatan dalam melakukan bongkar muat mempunyai sifat ketidak tetapan/fluktuasi, jika dilihat dari kecepatan rata-rata per bulannya, terkadang ada yang melebihi target, terkadang sesuai dengan target, dan bahkan ada yang berada di bawah target yang ditentukan. Menurut data yang penulis peroleh rata-rata GCR ditahun 2018 adalah sebanyak 24 box per jam dan VOR sebanyak 63 box per jam, hal tersebut menunjukan bahwa kecepatan rata-rata dalam bongkar muat petikemas tidak mencapai target yang ditetapkan KSO Terminal Petikemas Koja. Pada kenyataannya GCR di TPK Koja hanya 24 box per jam maka terdapat selisih 2 angka dibawah target yang seharusnya 26 box per jam. Dan pada VOR yang seharusnya 65 box per jam kenyataannya hanya 63 box per jam, terdapat selisih 2 angka dibawah target yang ditentukan.

Menurut hasil wawancara dengan Manning Operation bagian gate out di Terminal Petikemas Koja QCC nomor 2 (Panamax), nomor 4 (Post Panamax), dan nomor 5 (Post Panamax) mengalami masalah breakdown/kerusakan di cabin nya, sehingga menyebabkan QCC tidak bisa beroperasi selama satu bulan. Jadi dengan rusaknya 3 QCC (nomor 2, 4, 5) maka hanya 4 QCC yang dapat beroperasi (nomor 1, 3, 6, 7). Terjadinya kerusakan ini sangat mempengaruhi kinerja QCC dalam melancarkan operasi kegiatan bongkar muat, jika ada kapal besar datang yang mempunyai stack petikemas/tier dikapal tinggi maka hanya QCC nomor 6 dan 7 yang dapat beroperasi, seharusnya QCC nomor 4 dan 5 juga dapat beroperasi untuk kapal dengan stack petikemas/tier tinggi dikarenakan QCC nomor 4 dan 5 mengalami breakdown/kerusakan maka yang hanya dapat beroperasi hanya QCC nomor 6 dan 7 yang mempunyai tinggi lebih untuk bongkar petikemas tersebut. QCC nomor 1 dan 3 tidak bisa mengoperasikan karena mempunyai batasan ketinggian untuk bongkar petikemas yang ada dikapal. Hal tersebut cukup menggangu serta menghambat waktu pengerjaan bongkar muat. Masalah lainnya adalah Lock \& Unlock pada spreader patah saat mengangkat petikemas, hal tersebut menghambat kegiatan bongkar muat karena spreader harus segera diperbaiki oleh teknisi biasanya waktu untuk memperbaiki lock \& unlock 15 menit. Jika Quay Container Crane selalu dalam keadaan siap dan prima maka kelancaran akan bongkar muat dapat berjalan secara maksimal.

Jadi dapat disimpulkan bahwa kinerja Quay Container Crane berpengaruh terhadap kelancaran bongkar muat, bila Quay Container Crane dalam keadaan yang prima pada saat beroperasi maka kegiatan bongkar muat pun dapat berjalan dengan baik, sehingga kinerja nya maksimal, namun jika terjadi beberapa kendala (kerusakan atau alat macet) pada Quay Container Crane maka kelancaran dalam kegiatan bongkar muat menjadi tidak maksimal dan hasilnya pun tidak akan sesuai dengan target yang sudah ditentukan.

\section{KAJIAN PUSTAKA}

Menurut Veithzal Rivai (2005:97) Kinerja adalah hasil seseorang secara keseluruhan selama periode tertentu didalam melaksanakan tugas, seperti standar hasil kerja, target atau sasaran kriteria yang telah ditentukan terlebih dahulu dan telah disepakati bersama. Sedangkan menurut A.A. Anwar Prabu Mangkunegara (2005:9) dalam bukunya menerangkan bahwa Kinerja adalah hasil kerja secara kualitas dan kuantitas yang dicapai oleh seseorang karyawan dalam melaksanakan tugasnya sesuai dengan tanggung jawab yang diberikan kepadanya. Dari beberapa definisi diatas maka penulis dapat menyimpulkan bahwa kinerja adalah prestasi kerja atau hasil kerja (output) baik kualitas maupun kuantitas yang dicapai SDM per satuan periode waktu dalam melaksanakan tugas kerjanya sesuai dengan peran dan tanggung jawab yang diberikan kepadanya didalam perusahaan.

Salah satu factor penentu kinerja bongkar muat adalah peralatan bongkar muat yang memadai. Kegiatan bongkar muat di pelabuhan terdiri atas : Stevedoring yaitu kegiatan pembongkaran muatan dari kapal ke dermaga ataupun dari dermaga ke kapal dengan menggunakan crane kapal, crane dermaga dan alat pendukung lainnya, Cargodoring adalah kegiatan memindahkan muatan yang telah di bongkar dari kapal dari dermaga ke gudang/lapangan penumpukan, lalu disusun/stack di gudang ataupun lapangan penumpukan dan Receiving/Delivery yang merupakan kegiatan penerimaan dan penyerahan muatan dari gudang/lapangan penumpukan didaerah lini 1 dan disusun diatas kendaraan alat angkut darat untuk seterusnya disampaikan kepada consignee

Dalam kegiatan proses bongkar muat petikemas, diperlukan sebuah alat untuk mengangkat dan menurunkan petikemas yang disebut dengan Quay Container Crane. Alat tersebut dioperasikan oleh operator dan bantuan TKBM (Tenaga Kerja Bongkar Muat) untuk melakukan kegiatan tersebut. Dalam 1 Gang/Regu terdiri dari 12 orang TKBM. Quay Container Crane (QCC) adalah alat (Crane) yang digunakan untuk 
membongkar atau memuat petikemas dari kapal ke chassis headtruck maupun sebaliknya, memindahkan dari chassis headtruck ke atas kapal. Alat bongkar muat ini merupakan yang paling utama karena berada dipinggir dermaga tempat kapal petikemas sandar dan kinerja QCC di nilai dari kecepatan bongkar muat nya

Indikator yang menunjang kegiatan agar berjalan lancar sebagai berikut : QCC dalam keadaan prima, Operator yang bersertifikat dan ahli, Penggunaan alat sesuai Standar Operasional Prosedur, Tersedianya suku cadang jikalau ada kerusakan, Mekanik yang selalu dalam keadaan siap dan Perawatan/maintenance alat. Quay Container Crane ini berfungsi untuk membuat jangkauan QCC lebih jauh ke arah laut untuk menggapai petikemas yang ada di kapal. Jika sedang ada kapal crane akan bergerak turun (Boom Down) untuk melakukan operasi bongkar atau muat, sedangkan pada saat tidak beroperasi crane akan bergerak naik ke atas (Boom Up). Selain crane ada juga Cabin yang berfungsi untuk bergerak maju dan mundur bersama trolley sehingga operator di dalam dapat melihat posisi spreader pada saat akan mengangkat petikemas. Alat lain yaitu Gantry berguna untuk menggerakan QCC ke kanan dan ke kiri pada saat beroperasi. Motor Hoist Berguna untuk menggerakan spreader untuk menaik atau menurunkan petikemas pada saat sedang diangkat. Spreader Merupakan alat bantu bongkar muat yang dipasang di QCC, memiliki 4 sudut disetiap sudut memiliki pengunci yang disebut twistlock untuk dapat mengangkat petikemas dari atau ke kapal. Alat ini sangat membantu operator QCC untuk pengangkatan petikemas. Spreader tersedia dalam dua jenis yaitu Twinlift dan Singlelift.

Dalam melakukan kegiatan nya QCC mempunyai tiga pergerakan, yaitu Hoist Up \& Hoist Lower berguna untuk bergerak naik dan turunnya spreader, Trolley Cabin \& Spreader untuk bergerak maju dan mundur, Gantry berguna untuk menggeser dari kanan ke kiri. Terkadang salah satu dari tiga pergerakan tersebut ada yang bermasalah, karena pada setiap QCC itu mempunyai kendala nya masing-masing dan selalu berbeda. Saat ini QCC yang dimiliki dibagi menjadi tiga jenis, yaitu Panamax (QCC nomor 1, nomor 2, dan nomor 3), Post Panamax (QCC nomor 4 dan nomor 5), Super Post Panamax (QCC nomor 6 dn nomor 7).

Operator Quay Container Crane (Charlie) adalah orang-orang yang mempunyai keahlian khusus untuk mengoperasikan QCC, di KSO TPK koja saat ini terdapat 37 orang operator QCC yang terbagi menjadi 4 grup shift (A, B, C, D). Operator crane tersebut dilatih di Balai Pendidikan \& Pelatihan (BPL) Pelindo 2 untuk mendapatkan sertifikat keahlian. Setiap operator crane harus memiliki keahlian khusus dalam pelatihan yang telah dilakukan agar dapat terhindar dari kejadian yang tidak diinginkan. Setiap terminal pasti menginginkan alat bongkar muat yang selalu dalam kondisi prima guna meluncurkan operasi dengan lancar tanpa adanya gangguan teknis dari alat-alat bongkar muat yang digunakan. Penggunaan alat bongkar muat yang secara terusmenerus tentunya akan membuat kondisi alat tersebut menjadi tidak semaksimal seperti sebelumnya. Oleh sebab itu diperlukan perawatan rutin agar kondisi alat bongkar muat selalu dalam kondisi yang prima.

Untuk perawatan yang ada di KSO TPK Koja (sumber divisi teknik/workshop). Perawatan yang dilakukan pada mesin QCC; Pengecekan pada mesin gantry, Pengecekan kabel mesin gantry, Pengecekan oli pada mesin gantry, Pengecekan saringan udara, Pengecekan carbon bras pada motor gantry, Pengecekan rel sliding dan Pengecekan kondisi baut, twistlock.

Dalam melakukan kegiatan bongkar dan muat harus selalu diperhatikan segala aspek dalam menunjang kelancaran operasi agar dapat berjalan sesuai dengan tujuan. Menurut Dirk Koleangan (2008:241) dalam buku Sistem Petikemas menjelaskan bahwa kegiatan Bongkar Muat adalah kegiatan memindahkan barang-barang dari alat angkut darat dan untuk melaksanakan kegiatan pemindahan muatan tersebut dibutuhkan tersedianya fasilitas atau peralatan yang memadai dalam suatu cara atau prosedur pelayanan. Kelancaran bongkar muat diukur melalui kinerja semua peralatan bongkar muat dan dinyatakan dengan banyaknya petikemas yang dapat di bongkar dan dimuat oleh Quay Container Crane atau dinyatakan dengan kecepatan bongkar muat nya yang menggunakan satuan GCR ( Gross Crane Rate ) dan VOR, semakin banyak output yang dihasilkan maka semakin berkualitas terminal petikemas tersebut dan tentu nya akan banyak pula perusahaan pelayaran yang akan melakukan bongkar muat petikemas di terminal. GCR adalah banyaknya box petikemas yang dapat di pindahkan oleh satu buah crane dalam waktu 1 (satu) jam. Semakin tinggi angka GCR, maka semakin tinggi kualitas kinerja crane dalam melaksanakan bongkar muat. GCR TPK koja 26 box per jam. serta VOR ( Vessel Operating Rate ), VOR menunjukan kinerja operasi bongkar muat. VOR adalah banyaknya box petikemas yang mampu dimuat atau di bongkar dari dalam palka oleh pihak terminal terhadap satu buah kapal dalam waktu satu jam. Sama seperti GCR, semakin tinggi angka VOR maka semakin tinggi kualitas bongkar muat. VOR TPK Koja 65 box per jam. 
Tabel 1 Data GCR dan VOR Petikemas tahun 2018

\begin{tabular}{lll}
\multicolumn{1}{c}{ Month } & \multicolumn{2}{l}{ GCR } \\
\hline Januari & 23.20 & 64.23 \\
\hline Februari & 26.44 & 65.40 \\
\hline Maret & 26.09 & 66.73 \\
\hline Aplil & 25.10 & 61.40 \\
\hline Mei & 26.01 & 65.10 \\
\hline Juni & 25.05 & 60.68 \\
\hline Juli & 26.07 & 70.31 \\
\hline Agustus & 22.27 & 57.04 \\
\hline September & 21.28 & 60.36 \\
\hline Oktober & 25.03 & 61.97 \\
\hline November & 26.10 & 63.07 \\
\hline Desember & 26.03 & 66.30 \\
\hline Rata-Rata & $\mathbf{2 4 . 8 0}$ & $\mathbf{6 3 . 5 4}$
\end{tabular}

(sumber: KSO TPK Koja tahun 2018)

\section{Penelitian terdahulu}

Penelitian yang dilakukan oleh (Sumarzen Marzuki, 2008) menyatakan bahwa produktivitas alat bongkar muat kontainer pada dasarnya penting, karena mendukung keberhasilan masuk dan keluar kapal. Biaya efektifitas waktu yang muncul selama pemuatan dan pembongkaran kontainer memberikan pengaruh terhadap efisiensi dan efektifitas dalam setiap pekerjaan. Produktivitas di pelabuhan kontainer menjadi ukuran kerja di pelabuhan kontainer. Teknik analisis yang digunakan dalam penelitian ini adalah Confirmatory Factor Analysis dan Full Model dari Structural Equation Model (SEM) yang didukung oleh SPSS 14, AMOS 4.01 dan MANOVA.

Sedangkan penelitian yg dilakukan oleh (Hendra Gunawan, Suhartono dan Martinus Edy Sianto, 2008) menerangkan bahwa dalam melakukan aktivitas pengiriman barang, perusahaan pelayaran menggunakan kontainer sebagai alternatif agar barang tersebut terlindungi dengan baik. PT Pelayaran Meratus merupakan salah satu perusahaan pelayaran yang melakukan aktivitas pengiriman barang dengan menggunakan kontainer. Pengiriman dengan menggunakan kontainer dilakukan di dermaga petikemas. Penelitian ini bertujuan untuk mendapatkan suatu model kuantitatif yang dapat digunakan untuk mengetahui faktor-faktor yang memberikan pengaruh secara signifikan terhadap produktivitas bongkar muat. Metode yang digunakan untuk menyelesaikan permasalahan adalah metode regresi linier berganda dengan dummy variable. Dilakukan 4 tahap untuk analisis model regresi yang telah diperoleh.

Penelitian yang dilakukan oleh (Mudjiastuti Handajani, 2004) menerangkan bahwa Pelabuhan Tanjung Emas Semarang merupakan pelabuhan besar, di samping melayani angkutan penumpang dan barang umum, juga melayani bongkar muat peti kemas. Volume pengiriman barang menggunakan petikemas melalui pelabuhan Tanjung Emas terus meningkat dari tahun ke tahun. Namun, pelayanan peti kemas pada terminal petikemas Pelabuhan Tanjung Emas Semarang saat ini mengalami beberapa hambatan yang mempengaruhi kecepatan pelayanan petikemas. Hambatan tersebut disebabkan antara lain: (1) kurang maksimalnya penggunaan gantry crane dan rubber tyred gantry dalam melayani bongkar muat peti kemas, (2) penataan peti kemas yang kurang teratur di lapangan penumpukan, (3) waktu pelayanan truk dari luar yang membawa peti kemas ekspor yang bersamaan dengan chassis truck yang melayani pemuatan ke kapal, sehingga memperlambat suatu proses; hal yang sama juga terjadi pada proses bongkar (impor), dan (4) jumlah chassis truck tidak memenuhi konfigurasi standar operasional. Penelitian ini bertujuan meningkatkan efisiensi pelayanan peti kemas dengan cara memperbaiki sistem penataan peti kemas di container yard sesuai dengan urutan pemuatan kapal dan memberikan prakiraan jumlah chassis truck yang digunakan untuk mencapai produksi gantry crane yang optimal. Metode penelitian yang digunakan adalah pengumpulan data primer melalui survei di lapangan dan data sekunder yang diperoleh dari instansi terkait. Analisis data dilakukan dengan menggunakan teori antrean, sedangkan prakiraan arus peti kemas dengan perangkat lunak SPSS. 


\section{METODE}

Penelitian ini berlokasi di Kerja Sama Operasional (KSO) Terminal Petikemas Koja di Jl. Digul No.1, Tanjung Priok, Jakarta 14310, Indonesia. Waktu penelitian mulai dari November 2018 -Januari 2019. Populasi dalam penelitian ini ialah Operator Quay Container Crane yang berjumlah 37 responden. Teknik pengambilan sampel (Teknik Sampling) dalam penelitian ini menggunakan teknik Nonprobability yaitu sampel jenuh. Jadi sampel dalam penelitian ini adalah seluruh operator Quay Container Crane TPK Koja yang berjumlah 37 orang. Metode penelitian yaitu Data Kuantitatif. Sumber Data adalah Data Primer dan sekunder. Data primer dalam penelitian berasal dari jawaban responden atas kusioner. Sedangkan data Sekunder, meliputi bukubuku bacaan, literatur-literatur, jurnal dan berbagai sumber yang sudah ada.

\section{HASIL DAN PEMBAHASAN}

Dari data yang diperoleh didapatkan hasil data mengenai usia responden. Dimana data usia yang diperoleh terbanyak adalah pada usia 41 - 45 tahun sebanyak 14 orang dengan persentase sebesar 37,8\%, responden yang berusia $36-40$ tahun sebanyak 11 orang dengan persentase sebesar $29,8 \%$, responden yang berusia >45 tahun sebanyak 6 orang dengan persentase 16,2\%, responden yang berusia 31 - 35 tahun sebanyak 4 orang dengan persentase $10,8 \%$, dan responden yang berusia terendah $26-30$ tahun sebanyak 2 orang dengan persentase 5,4\%. Dari data yang telah diolah diatas dapat disimpulkan bahwa sebagian besar responden operator QCC di KSO Terminal Petikemas Koja berusia 41 - 45 tahun.

Dari segi tingkat pendidikan diperoleh bahwa SMA sebanyak 27 orang responden dengan persentase 73 $\%$, responden dengan pendidikan D3 sebanyak 8 orang responden dengan persentase $21,6 \%$, responden dengan pendidikan S1 sebanyak 2 orang responden dengan persentase 5,4 \% dan responden dengan pendidikan S2 0 orang dengan persentase $0 \%$. Jadi dapat ditarik kesimpulan bahwa sebagian besar responden operator QCC di KSO Terminal Petikemas Koja memiliki pendidikan terakhir SMA dengan persentase sebanyak $73 \%$.

Dari segi lama bekerja dapat diketahui bahwa lamanya responden bekerja di KSO TPK Koja adalah 6 10 tahun sebanyak 3 orang dengan persentase $8,1 \%$, responden lamanya bekerja $11-15$ tahun sebanyak 11 orang dengan persentase 29,8\%, dan responden yang bekerja > 15 tahun sebanyak 23 orang dengan persentase $62,1 \%$. Dari data diatas dapat disimpulkan bahwa berdasarkan lama bekerja responden di KSO TPK Koja terbanyak yaitu selama $>15$ tahun dengan persentase $62,1 \%$ dan terendah pada $6-10$ tahun sebanyak 3 orang dengan persentase $8,1 \%$.

Berdasarkan Lama Kerja Sebagai Operator dapat diketahui bahwa lamanya responden yang bekerja sebagai operator QCC adalah 1 - 3 tahun sebanyak 12 orang dengan persentase 32,4\%, responden yang bekerja $4-5$ tahun sebanyak 14 orang dengan persentase $37,9 \%$, responden yang bekerja selama $5-10$ tahun sebanyak 6 orang dengan persentase $16,2 \%$, dan responden yang bekerja selama $11-15$ tahun sebanyak 5 orang dengan persentase 13,5\%. Dari data hasil responden diatas dapat disimpulkan bahwa berdasarkan lamanya kerja responden sebagai operator QCC terbanyak ialah pada $4-5$ tahun yaitu sebanyak 14 orang atau dengan persentase $37,9 \%$ dan terendah yaitu $11-15$ tahun sebanyak 5 orang atau dengan persentase $13,5 \%$.

Hasil uji Validitas dan Reliabilitas menggunakan SPSS menunjukkan semua butir pertanyaan valid dan reliable.

\section{Pembahasan dan Uji Hipotesis Pengaruh Kinerja Quay Container Crane (X) Terhadap Kelancaran Bongkar Muat (Y) Petikemas di KSO Terminal Petikemas Koja Tahun 2018}

1. Analisis Regresi Linear Sederhana

Tabel 2 Coefficients

\begin{tabular}{|c|c|c|c|c|c|c|}
\hline \multirow[b]{2}{*}{ Model } & & \multicolumn{2}{|c|}{ Unstandardized Coefficients } & \multirow{2}{*}{$\begin{array}{c}\text { Standardized Coefficients } \\
\text { Beta }\end{array}$} & \multirow[b]{2}{*}{$\mathrm{t}$} & \multirow[b]{2}{*}{ Sig. } \\
\hline & & B & Std. Error & & & \\
\hline 1 & (Constant) & 9.679 & 6.422 & & 1.507 & .141 \\
\hline & Kinerja QCC & .696 & .153 & .610 & 4.556 & .000 \\
\hline
\end{tabular}


a. Dependent Variable: Kelancaran Kegiatan Bongkar Muat

Sumber : Hasil olahan SPSS Ver. 24.00

Dari hasil perhitungan dengan menggunakan metode SPSS diatas dapat diketahui bahwa analisis regresi dan analisis korelasi keduanya mempunyai hubungan yang kuat dan mempunyai keeratan antara masingmasing variabel. Analisis regresi linear sederhana digunakan untuk mengetahui seberapa besar pengaruh kinerja quay container crane (X) terhadap kelancaran kegiatan bongkar muat (Y). Sebelum itu maka terlebih dahulu dicari model regresinya dengan persamaan regresi linear sederhana dengan rumus : $\mathbf{Y}=\mathbf{a}+\mathbf{b X}$. Berdasarkan tabel diatas dapat dilihat nilai a sebagai konstanta sebesar 9,679 dan untuk nilai b sebesar 0,696. Sehingga diperoleh persamaan regresi linear sederhana yaitu: $\mathbf{Y}=\mathbf{9 , 6 7 9}+\mathbf{0 , 6 9 6 X}$

Dengan model persamaan regresi yang dapat dituliskan dari hasil tersebut adalah sebagai berikut:

a. Nilai konstanta (a) sebesar 9,679 menyatakan bahwa apabila tanpa kinerja QCC maka diperkirakan kelancaran kegiatan bongkar muat bernilai sebesar a $=\mathbf{9 , 6 7 9}$.

b. Nilai koefisien pengaruh kinerja quay container crane (b) bernilai positif yaitu sebesar $\mathrm{b}=\mathbf{0 , 6 9 6}$ artinya adalah kinerja QCC (variabel X) berpengaruh positif terhadap kelancaran kegiatan bongkar muat. Jika kinerja QCC (variabel X) bertambah, maka kelancaran kegiatan bongkar muat (variabel Y) pada KSO Terminal Petikemas Koja akan mengalami peningkatan sebesar 0,696.

c. Apabila $X$ diketahui nilainya, misalnya $X=100$, maka kelancaran kegiatan bongkar muat menjadi $\mathrm{Y}=\mathrm{a}$ + bX. Y $=9,679+(0,696)(100)=79,279$

\section{Analisis Koefisien Korelasi}

Teknik korelasi ini digunakan untuk mencari hubungan dan membuktikan pengaruh hubungan variabel independen dengan variabel dependen, maka perlu dilakukan analisis korelasi antara variabel penelitian secara individual yang hasilnya dapat dilihat pada tabel di bawah ini :

Tabel 3. Hasil Analisis Koefisien Korelasi

\begin{tabular}{llrr}
\hline & & Kinerja QCC & Kelancaran Bongkar Muat \\
\hline Kinerja QCC & \multicolumn{1}{l}{ Pearson Correlation } & 1 & $.610^{* * *}$ \\
\cline { 2 - 4 } & Sig. (2-tailed) & & .000 \\
\cline { 2 - 4 } & $\mathrm{N}$ & 37 & 37 \\
\hline \multirow{2}{*}{$\begin{array}{l}\text { Kelancaran Bongkar } \\
\text { Muat }\end{array}$} & Pearson Correlation & $.610^{* * *}$ & 1 \\
\cline { 2 - 4 } & Sig. (2-tailed) & .000 & 37 \\
\cline { 2 - 4 } & $\mathrm{N}$ & 37 & \\
\hline
\end{tabular}

**. Correlation is significant at the 0.01 level (2-tailed).

Sumber : Hasil olahan SPSS Analisis Regresi Linear Sederhana (SPSS Ver. 24.00)

Dari tabel diatas diketahui bahwa hubungan (korelasi) antara kinerja quay container crane terhadap kelancaran kegiatan bongkar muat sebesar 0,610 $\left(\mathrm{r}_{\mathrm{xy}}\right)$ dimana berada pada interval 0,60-0,799 (pada tabel IV.39) yang berarti membuktikan bahwa pengaruh variabel $\mathrm{X}$ terhadap variabel $\mathrm{Y}$ menunjukan pengaruh yang kuat. Berdasarkan tabel koefisien korelasi diatas ternyata kedua variabel mempunyai pengaruh yang signifikan karena sig 2 tail (signifikan) kurang dari < 0,05 dengan data yaitu kinerja QCC sebesar $(0,00)$ dan kelancaran bongkar muat sebesar $(0,00)$.

\section{Analisis Koefisien Penentu}

Untuk mengetahui seberapa besar persentase kinerja QCC terhadap kelancaran kegiatan bongkar muat petikemas dapat dilakukan dengan menghitung koefisien penentu, dengan rumus menurut Sugiyono (2015:231) sebagai berikut: $\mathrm{KP}=\mathrm{r}^{2} \times 100 \%$

Keterangan :

$\mathrm{KP}=$ Koefisien Penentu

$\mathrm{r}^{2}=$ Koefisien Korelasi yang dikuadratkan

Dengan rumus diatas dapat ditulis sebagai berikut :

$$
\begin{aligned}
\mathrm{KP} & =\mathrm{r}^{2} \times 100 \% \\
& =(0,610)^{2} \times 100 \% \\
& =0,3721 \times 100 \%
\end{aligned}
$$


Tabel 4 Hasil Analisis Koefisien Penentu

\begin{tabular}{lcccc}
\hline \multicolumn{5}{c}{ Model Summary } \\
\hline Model & $\mathrm{R}$ & $\mathrm{R}$ Square & $\begin{array}{c}\text { Adjusted R } \\
\text { Square }\end{array}$ & $\begin{array}{c}\text { Std. Error of the } \\
\text { Estimate }\end{array}$ \\
\hline 1 & $.610^{\mathrm{a}}$ & .372 & .354 & 4.01817 \\
\hline a. Predictors: (Constant), Kinerja QCC & & \\
\hline
\end{tabular}

Sumber : Hasil olahan kuesioner (SPSS Ver. 24.00)

Berdasarkan hasil pengolahan dengan menggunakan metode SPSS diketahui nilai dari koefisien penentu (KP) yang dapat digunakan untuk mengetahui besarnya proporsi variabel independen dalam menjelaskan variabel dependen. Nilai koefisien penentu $R$ square sebesar 0,372 yang menunjukan bahwa 37,2 \% kontribusi kinerja quay container crane terhadap kelancaran kegiatan bongkar muat sedangkan sisanya sebesar $62,8 \%$ (100\% - 37,2\%) berhubungan oleh variabel lain yang tidak di ukur dalam penelitian ini.

\section{Analisis Uji Hipotesis}

Berdasarkan perhitungan yang telah dilakukan, didapatkan nilai $\mathrm{t}$ hitung adalah sebesar 5,746 dan nilai $\mathrm{t}$ tabel adalah sebesar 2,030. Karena nilai $\mathrm{t}_{\text {hitung }}>\mathrm{t}$ tabel yaitu 5,746 > 2,030, maka $\mathrm{H}_{0}$ ditolak dan $\mathrm{H}_{\mathrm{a}}$ diterima, artinya terdapat pengaruh positif yang signifikan antara variabel X (kinerja QCC) terhadap variabel $\mathrm{Y}$ (kelancaran kegiatan bongkar muat). Jadi diduganya ada pengaruh yang positif antara kinerja quay container crane terhadap kelancaran kegiatan bongkar muat adalah terbukti benar.

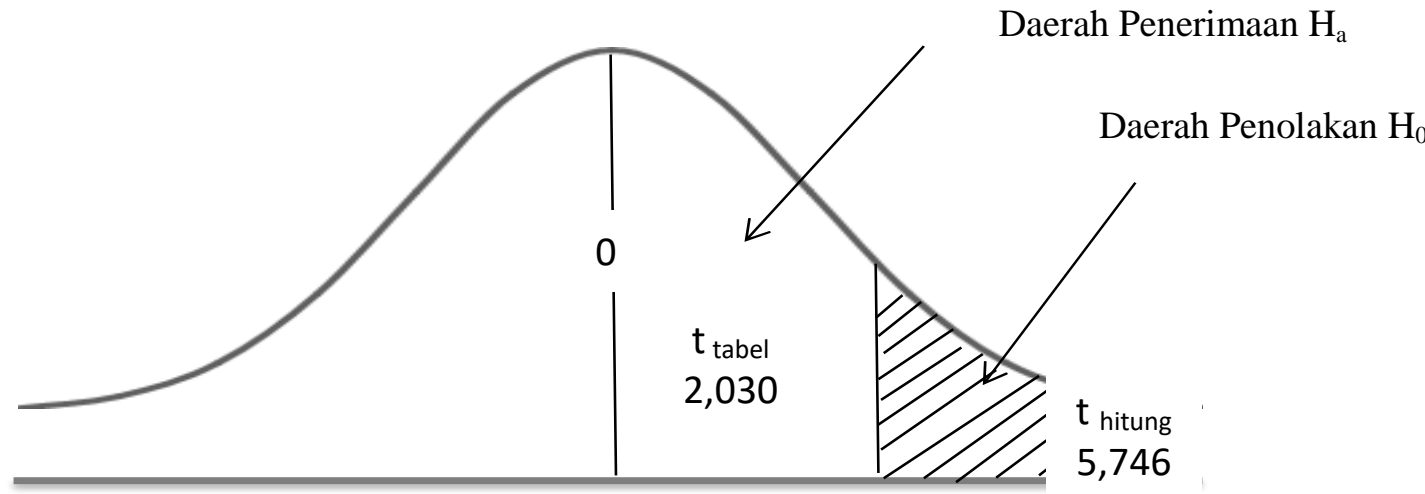

Gambar1. Kurva Distribusi Uji t Sumber : diolah penulis

Dari gambar diatas menunjukan bahwa $t_{\text {hitung }}$ berada di daerah penolakan $\mathrm{H}_{0}$. Artinya ada pengaruh yang positif dan signifikan dikarenakan total $t_{\text {hitung }}$ lebih besar daripada total $t_{\text {tabel }}$ antara variabel $\mathrm{X}$ (kinerja quay container crane) dan variabel Y (kelancaran kegiatan bongkar muat petikemas).

\section{KESIMPLAN DAN SARAN}

Berdasarkan hasil analisis dan pembahasan pada bab sebelumnya tentang pengaruh kinerja quay container crane (variabel X) terhadap kelancaran kegiatan bongkar muat petikemas (variabel Y) di KSO Terminal Petikemas Koja tahun 2018 adalah sebagai berikut :

1) Dalam analisis data diatas menunjukan bahwa Kinerja Quay Container Crane pada KSO Terminal Petikemas Koja termasuk kedalam kategori penilaian sangat baik dengan rata-rata sebesar 4,41 sehingga mampu memberi pengaruh sangat baik terhadap perusahaan sehingga dengan adanya pengaruh yang sangat baik ini perusahaan mampu memberikan pelayanan yang baik kepada pemakai jasa terminal petikemas. 
2) Tingkat kelancaran kegiatan bongkar muat petikemas termasuk dalam kategori baik berdasarkan hasil kuesioner pada kriteria penilaian dengan rata-rata sebesar 4,14 sehingga mampu memberi pengaruh yang baik terhadap perusahaan, ini menunjukan bahwa tingkat kelancaran kegiatan bongkar muat rata-rata sudah baik.

3) Berdasarkan hasil analisis penelitian, maka penulis dapat menyimpulkan sebagai berikut : Regresi Sederhana diketahui bahwa : $\mathbf{Y}=\mathbf{9 , 6 7 9}+\mathbf{0 , 6 9 6 X}$ Artinya, jika terjadi perubahan kinerja QCC bertambah, maka kelancaran kegiatan bongkar muat petikemas akan mengalami peningkatan nilai koefisien sebesar $\mathbf{0 , 6 9 6 .}$

a. Dari analisis perhitungan pada SPSS versi 24 diketahui bahwa koefisien korelasi $\mathbf{r}_{\mathbf{x y}}=\mathbf{0 , 6 1 0}$, Jadi dapat disimpulkan bahwa antara variabel X (kinerja QCC) dengan variable Y (kelancaran kegiatan bongkar muat) pada KSO Terminal Petikemas Koja tahun 2018 memiliki pengaruh yang kuat sesuai dengan tabel interprestasi koefisien korelasi.

b. Dari perhitungan uji korelasi dan koefisien penentu maka dapat diperoleh nilai $\mathbf{K P}=\mathbf{3 7 , 2} \%$.

Berdasarkan perhitungan pada pembahasan, pengaruh variable X (kinerja QCC) dengan variabel Y (kelancaran kegiatan bongkar muat) sebesar 37,2 \% sedangkan sisanya sebesar 62,8 \% (100\% - 37,2\%) yang disebabkan oleh variabel lain yang tidak diukur dalam penelitian ini.

c. Dari perhitungan hasil uji hipotesis menunjukan bahwa nilai

$t_{\text {hitung }}>t_{\text {tabel }}$ atau 5,746 $>2,030$, maka $\mathrm{H}_{0}$ ditolak dan diterima, artinya terdapat pengaruh positif dan signifikan antara variabel X (kinerja QCC) terhadap variabel Y (kelancaran kegiatan bongkar muat) di KSO Terminal Petikemas Koja tahun 2018. 


\section{Daftar Pustaka}

Arikunto, S. (2013). Prosedur Penelitian: Suatu Pendekatan Praktik. Jakarta: Rineka Cipta.

Gunawan Hendra, Suhartono dan Martinus Edy Sianto. (2008). Analisis Faktor-Faktor Yang Berpengaruh Terhadap Produktivitas Bongkar Muat Kontainer Di Dermaga Berlian Surabaya (Studi Kasus Pt. Pelayaran Meratus). (Studi Kasus Pt. Pelayaran Meratus), volume 7 nomor 1.

Gunawan, Herry. (2014). Pengantar Transportasi dan Logistik. Jakarta: PT. Raja Grafindo Persada.

Handajani, Mudjiastuti. (2004). Analisis Kinerja Operasional Bongkar Muat Peti Kemas Pelabuhan Tanjung Emas SemaranG. Jurnal Transportasi, volume 4 nomor 1, 1-12.

Hasibuan, M.S. (2008). Manajemen Dasar, Pengertian dan Masalah. Jakarta: PT. Bumi Aksara.

Indrawan, W. (2000). Kamus Lengkap Bahasa Indonesia. Jombang: Lintas Media.

Koleangan, Dirk. (2008). Sistem PetiKemas (Container System). Jakarta.

Lasse, D.A. (2014). Manajemen Muatan Aktivitas Rantai Pasok Di Area Pelabuhan (Cetakan ke). Jakarta: PT. Raja Grafindo Persada.

Lesmini, Lis dan Budi Purwanto. (2016). Ekonomi Maritim \& Sumber Daya Manusia Indonesia. Jurnal Manajemen Bisnis Transportasi Dan Logistik, 2 nomor 3.

Mangkunegara, A.P. (2005). Manajemen Sumber Daya Manusia. Bandung: PT. Remaja Rosdakarya.

Manullang, M. (2001). Dasar-Dasar Manajemen. Yogyakarta: Gadjah Mada University Press.

Martono, Nanang. (2016). Metode Penelitian Kuantitatif. Jakarta: Rajawali Pers.

Marzuki, Sumarzen. (2008). Pengaruh Faktor Kelembagaan, Fisik Dan Eksternal Terhadap Produktivitas Bongkar Muat Petikemas (. Alumni Mahasiswa. Program Doktor Ilmu Ekonomi Pascasarjana Untag 1945 Surabaya, 4 nomor 4.

Sihombing, Sarinah dan A.J.Muljadi. (2014). Pengantar Manajemen Edisi Revisi. Jakarta: Mitra Wacana Media.

Sihombing, Sarinah, R.Simon Gultom, \& Sonya Sidjabat. (2015). Manajemen Sumber Daya Manusia. Jakarta: In Media.

Siregar, Sofyan. (2013). Metode Penelitian Kuantitatif Dilengkapi Dengan Perbandingan Perhitungan Manual dan SPSS. Jakarta: Prenadamedia Group.

Siregar, Sofyan. (2012). Metode Penelitian Kuantitatif Dilengkapi Dengan Perbandingan Perhitungan Manual dan SPSS. Jakarta: Prenadamedia Group.

Sugiyono. (2010). Metode Penelitian Kuantitatif, Kualitatif, dan R\&D. Bandung: CV. Alfa Beta.

Sugiyono. (2012). Metode Penelitian Kuantitatif, kualitatif dan R\&D. Bandung: CV. Alfa Beta.

Sugiyono. (2013). Metode Penelitian Manajemen. Bandung: CV. Alfa Beta.

Sugiyono. (2015). Metode Penelitian Pendidikan (Kuantitatif, kualitatif dan R\&D). Bandung: CV. Alfa Beta.

Terry, G.R. dan Rue, L. W. (2009). Dasar-Dasar Manajemen. PT. Bumi Aksara.

Veithzal, R. (2005). Manajemen Sumber Daya Manusia. Jakarta: Raja Grafindo Persada.

Wahono, D. (2015). Terminal Petikemas pada Pelabuhan Internasional Pantai Kijing di Kecamatan Sungai Kunyit Kabupaten Pontianak. Online Mahasiswa Universitas Tj. Pura, 39.

Yulianto, M.A dan Budi Setiono,. (2013). Efektifitas Bongkar Muat Petikemas Terhadap Kelancaran Arus Barang di PT. Nilam Port Terminal Indonesia (NPTI) Cabang Tanjung Perak Surabaya, volume 4 Nomor 1,38 .

Zatayu, Widya dan Budi Priyono. (2018). Optimalisasi Tenaga Kerja Bongkar Muat Terhadap Kelancaran Bongkar Muat Petikemas Di Pt Berlian Jasa Terminal Indonesia Cabang Surabaya, 9 nomor 1.

Website:

conversaindotama.com

Undang-Undang \& Peraturan:

- $\quad$ Undang - Undang No.1 Tahun 1970 tentang Keselamatan Kerja

- $\quad$ Peraturan Menteri No. Per. 05/ Men/ 1985 tentang Pesawat Angkat dan Angkut

- Peraturan Menteri No. Per. 09/ Men/ 2010 tentang Operator dan Petugas Pesawat Angkat dan Angkut

- $\quad$ Keputusan Presiden No. 52 Tahun 1987 pasal 1 Tentang Terminal Petikemas 